\title{
LA RENTA BÁSICA UNIVERSAL Y LOS PROGRAMAS ELECTORALES 2016 DE LOS PARTIDOS POLÍTICOS
}

\author{
María Luisa Soriano González \\ Universidad Pablo de Olavide, Sevilla
}

https://doi.org/10.33676/EMUI_nomads.56.11

Resumen: El trabajo se centra en una cuestión poco tratada, como es la renta básica universal y su relación con los actuales programas de los partidos políticos, con los que han concurrido a las elecciones generales, con una doble dimensión: a) lo que cada programa presenta y defiende acerca de esta renta o medidas similares (justificación, alcance y límites), y b) una vez esbozadas la idea y alcance de la renta en cada partido, el análisis comparativo de las diversas propuestas de los partidos, abundando en la cercanía o la distancia de tales propuestas con una renta básica universal

Palabras clave: renta básica universal, rentas de solidaridad, políticas sociales, igualdad social, soluciones a la pobreza.

\begin{abstract}
The work focuses on a little-treated issue, as it is the universal basic income and its relationship with existing programmes of the political parties, which have attended the general election, with a double dimension: (a) what each program presents and defends about this income or similar measures (justification, scope and limits), and b) once outlined the idea and scope of the income in each party, the comparative analysis of the various proposals of the parties, abounding in the closeness or distance of such proposals with a universal basic income
\end{abstract}

Keywords: universal basic income, income from solidarity, social policy, social equality, solutions to poverty.

\section{La renta básica universal: una cuestión permanente}

El debate sobre la renta básica ha resucitado desde que Van Parijs aglutinó a un grupo de investigadores en torno a este tema y escribió su trabajo de referencia sobre la libertad real y la renta básica, Una vía capitalista al comunismo (1986). No es que Van Parijs abriera un tema nuevo, sino que fijó la atención e impulsó el debate sobre una cuestión hasta cierto punto adormecida, aunque omnipresente en la historia de la filosofía jurídica y política: el derecho a una renta o ingreso mínimos sin condiciones y contraprestaciones. 
El derecho a la renta básica ha estado presente en filósofos y pensadores de todos los tiempos. Destacando al respecto propuestas concretas de Thomas Paine (1990), Maximilien Robespierre (1992), Charles Fourier (1973) y ya en el siglo XX numerosos autores. Desde el siglo XVIII sobre todo ha surgido en la conciencia de los espíritus avanzados la necesidad de completar las libertades individuales con unas condiciones mínimas de bienestar. En el siglo XIX socialistas moderados y radicales contrapusieron los derechos sociales a las libertades individuales defendiendo que éstas serían retóricas y falaces si no iban acompañadas de condiciones sociales y económicas (derechos sociales) que las hicieran posibles. La renta básica está presente en pensadores de todos los tiempos. También en la teorías jurídico-polííicas clásicas. Desde el liberalismo, el republicanismo, el socialismo, el comunismo se han realizado, en mayor o menor medida, aproximaciones a la renta básica. No es ésta patrimonio de una teoría concreta. Los estudiosos suelen coincidir en que el republicanismo es la concepción más próxima a la renta básica, o desde la que es más factible hacer una mejor fundamentación. (Soriano, R., 2011)

Quizás el lector poco advertido se sorprenda de la existencia de este debate y que haya quienes defiendan el derecho individual a una renta del Estado sin contraprestación alguna por el mero hecho de ser persona o ciudadano. Porque en la mente de muchos opera una correlación necesaria entre renta y trabajo considerando como consecuencia la improcedencia de la obtención de una renta sin trabajo previo. No se justifica la concesión de una renta sin la contraprestación en forma de trabajo. También sorprende que el Estado pueda disponer de tanto dinero para sufragar la renta, aunque sea mínima, de sus ciudadanos. Sorpresas habituales en quienes se enfrentan por vez primera al tema de la renta básica acompañadas de interrogantes, que van perdiendo fuerza cuando el no advertido lector se adentra en los estudios de renta básica y en las propuestas de simulaciones realizadas por economistas con distintos criterios de financiación. El interesado en el tema puede acceder a la Red Renta Básica en España, donde encontrará numerosos proyectos de simulación de la renta básica universal aplicada a España con distintos criterios y baremos. No en balde forman parte de esta red destacados y expertos economistas en la materia.

Esta sorpresa inicial va despareciendo cuando el lector advierte que la renta básica ha entrado en la agenda política de los Estados y los partidos políticos. También partidos políticos españoles que han conseguido que se cree en el Estado una subcomisión de renta básica. Destacan Esquerra Republicana e IU-Los Verdes en la promoción de la renta básica en el Estado español y en la Comunidad Autónoma Catalana. Actualmente ha sido reconocida jurídicamente en leyes de dos Estados: en el Estado de Alaska perteneciente a Estados Unidos de América y en el Estado de Brasil. En Alaska se introduce por vez primera 
la renta básica aprovechando los beneficios muy altos de la explotación petrolífera. Se distribuye anualmente un porcentaje de los dividendos que fluctúan en función de los réditos obtenidos y del número de habitantes del Estado. En Brasil la renta básica ha sido introducida por obra del presidente Lula da Silva: hay una legislación al respecto que establece plazos para su progresiva introducción. Fórmulas jurídicas muy próximas a la renta básica se encuentran ya en un buen número de Estados de distintos lugares de la geografía mundial.

Las ventajas del reconocimiento de la renta básica actuarían en todas las dimensiones y no solamente en el ámbito del derecho. Señalo los beneficios más relevantes.

En el orden social se habría dado un gran paso para la eliminación de la pobreza, al menos de la pobreza impuesta y no voluntaria, pues los ciudadanos independientemente de su trabajo y estatus gozarían de un mínimo vital para cubrir sus necesidades más esenciales.

En el orden económico y laboral aparecería una nueva tipología de trabajos y duración de los mismos -trabajos a tiempo completo 0 trabajos parciales, trabajos de mercado y trabajos voluntarios, etc.-, dependiendo de las aspiraciones laborales concretas en el ámbito del mercado de quienes ya tendrían garantizada la cobertura de sus necesidades básicas. Lo que contribuiría a la política de pleno empleo, que en estos momentos tanto preocupa a las sociedades y los Estados europeos. También los trabajadores ostentarían una posición de mayor independencia respecto a sus empleadores, puesto que la respuesta empresarial a una actitud de resistencia del trabajador ya no llevaría al trabajador a cambiar la dependencia del empleador por la dependencia de la limosna insegura de un nuevo "amo", el Estado. El trabajador tendría siempre cubiertas las espaldas con el salario o renta mínimos.

En el orden psicológico los ciudadanos se sentirían más libres y con mayores posibilidades en la realización de sus programas de vida. No sufrirían la incertidumbre de un trabajo inseguro y cada vez más escaso, el miedo al estigma social si es despedido de su trabajo y las amarguras -para él y la familia- derivadas de la inclusión, si llegara el caso, en las crecientes masas de parados.

Mi definición de la renta básica universal en un trabajo anterior sobre el derecho de subsistencia en Luigi Ferrajoli y su equiparación con la renta básica universal era la siguiente: "La renta básica en pocas palabras es el derecho individual e incondicionado a recibir una prestación del Estado para atender a las necesidades básicas". (Soriano, M.L., 2012: 232) Una definición sencilla es la de los profesores Daniel Raventós, presidente de la Red Renta Básica en España, y de Ramón Soriano expresada en la presentación de un debate sobre la renta básica: "La renta básica es una asignación monetaria incondicional para toda la 
ciudadanía y residentes acreditados".' (Raventós, D., y Soriano, R., 2010: 190) Ramón Soriano, por su parte, amplía la definición de esta manera: "un ingreso mínimo incondicionado para los ciudadanos y residentes de pleno derecho, compatible con otros ingresos, que tiene la finalidad de garantizar su derecho a la subsistencia y su libertad real, satisfaciendo sus necesidades más elementales". (Soriano, R., 2012: 19) Una definición más amplia y autorizada es la de la asociación Basic Income Earth Network (BIEN): "ingreso incondicionado pagado a todos individualmente, sin sujetarlo a ningún test de recursos o al requisito de trabajar". Lo importante en la definición es precisar que se trata de un derecho incondicionado y que, por lo tanto, no exige una condición o situación determinadas del beneficiario/a de la renta -estar en paro, escasa retribución, enfermedad o incapacidad, etc.- para recibir la prestación del Estado. La persona o el ciudadano es titular de la renta de la misma manera que lo es de las libertades: por ser persona 0 ciudadano del Estado.

En el citado trabajo de D. Raventós y R. Soriano se señalan los caracteres de esta renta: a) individual (no se concede únicamente a la familia $U$ hogar familiar como es frecuente en los subsidios), b) incondicional, cualidad que la separa de los subsidios sociales que exigen demostrar algunas carencias materiales o una actitud activa del subsidiado ante el trabajo, c) universal, pues todos los ciudadanos y residentes estables pueden acceder a ella, d) básica, porque se trata de un ingreso modesto a partir del cual pueden sumarse otras rentas provenientes de distintas fuentes, e) periódica (mensual o anual como periodicidad habitual), f) en efectivo (en especie tendría el problema de restringir las posibilidades que ofrece el dinero efectivo), g) compatible con otras rentas como los salarios del trabajo, h) independiente de estatus y nivel de renta, situación ante el trabajo, etc., de la persona, i) estatal, aunque nada impide que una institución jurídico-política por encima del Estado (la Unión Europea, p. e.) o por debajo (una comunidad autónoma, p.e.) otorgue una renta básica a los ciudadanos pertenecientes a un determinado territorio. (Raventós, D., Soriano, R., 2012: 193-194).

\section{La renta básica universal y los programas electorales 2016 de los partidos políticos.}

Me centraré en el análisis de las propuestas electorales de los cuatro partidos con mayor representación parlamentaria. Pero no voy a emplear el criterio numérico de la representación parlamentaria de los

\footnotetext{
1 Definición que consta en la introducción de ambos autores al interesante "Debate de RIPP" sobre la renta básica, en el que participaron los expertos en el tema como Arcarons, Lo Vuolo, Rey, Yanes y Zubero. Véase "El Debate de RIPP", Revista Internacional de Pensamiento Político, 5, 189-211.
} 
partidos para establecer un orden de prioridad en este apartado del trabajo, sino que el criterio será el de la mayor lejanía de los partidos en la defensa de una renta básica universal. Comenzaré con el partido más alejado de esta renta, el Partido Popular, y concluiré con el más próximo, Podemos.

\subsection{Partido Popular: igualdad en la recepción de las prestaciones sociales}

Es el partido que se muestra menos cercano a una renta básica universal. Se limita a una regulación mejor de las rentas de inserción social y a la promoción de la igualdad entre las personas subsidiadas por las Comunidades Autónomas (sin especificar el modo). No plantea realmente algo nuevo, sino la mejora de la administración de lo existente en su programa electoral." Bajo el título "Combatir la exclusión social" propone una serie de medidas de carácter general y sin arbitrar acciones concretas, entre las que señala: "aprobar una ley básica de servicios sociales" (medida $1^{a}$ ), "armonización del sistema de servicios sociales" (medida $2^{a}$ ), "coordinación del sistema de ayudas para evitar la pobreza y exclusión social" (medida $3^{a}$ ), "mayor calidad y transparencia de los servicios sociales" (medida $6^{a}$ ), "oficina de innovación social" (medida $7^{a}$ ), "servicios sociales más cercanos" (medida $8^{\mathrm{a}}$ ), "herramientas para conocer la dinámica de la exclusión social" (medida 9a). Como ve el lector una serie de medidas sin acompañamiento de acciones concretas. Entre estas medidas destacan "Plan de Inclusión social 2016-2020" (medida 10) y "coordinación de las rentas mínimas de inserción social de las distintas Comunidades Autónomas para favorecer la igualdad de oportunidades" (medida 20 ${ }^{a}$ ). ${ }^{3}$

Aunque el PP sea el partido más alejado de una renta básica universal y menos innovador en la protección social de los ciudadanos, su propuesta de la igualdad de los españoles en la recepción de subsidios con independencia de la Comunidad Autónoma a la que pertenezcan es una medida muy necesaria y un gran avance. Hoy en día asistimos a una situación caótica, porque a la fragmentación de los subsidios de toda clase y los costes enormes de su gestión se une la quiebra de la igualdad de los españoles ante situaciones de emergencia, porque la ayuda para salir de la misma depende de los programas sociales de la Comunidad Autónoma donde se resida. Ya varias ONGs se han pronunciado en el sentido corrector de vincular la emergencia a la persona directamente, con independencia del territorio donde viva. Tal es la propuesta de un informe de Cáritas Española. (2015).

\footnotetext{
2 PROGRAMA_ELECTORAL_PP_2016.PDF

3 Pueden verse esta serie de medidas en el programa electoral citado, pp. 123-126.
} 


\subsection{Ciudadanos: complemento salarial garantizado}

Ciudadanos defiende un impuesto negativo bajo la fórmula de un complemento salarial anual garantizado (CSAG), es decir, una devolución periódica, según se determine, como complemento salarial de las personas que cumplan con determinados requisitos. Está contemplado para los trabajadores con empleos precarios y salarios más bajos. Este complemento tendrá diferentes tramos según la renta y la situación familiar de los beneficiarios, predominando si se tiene o no hijos a cargo

En su programa electoral 2016 Ciudadanos contempla 350 soluciones para cambiar a España a mejor (título del programa), que divide en varias partes: a) Reconstruir la clase media y trabajadora, b) Unión e igualdad de todos los españoles, c) Invertir en el presente para ganar el fututo, d) Regeneración democrática y lucha contra la corrupción, y e) Más protagonismo de España en el mundo y lucha contra el terrorismo. En la primera parte, art. 42, plantea un complemento salarial garantizado con este enunciado: "Un complemento salarial garantizado para ayudar a los trabajadores con menores ingresos a que tengan un sueldo digno. Será una devolución de Hacienda para luchar contra la pobreza laboral. En España existen 7,5 millones de trabajadores que no llegan al salario mínimo anual por lo que es prioritario reconstruir la clase media trabajadora y luchar contra la economía sumergida. La cuantía del complemento salarial será variable en función de los ingresos y condiciones familiares como por ejemplo el número de hijos."

Todo queda indeterminado, pues habría que trazar una línea en los ingresos por debajo de la cual se percibiría tal salario complementario, aunque parece deducirse del citado artículo que el ingreso complementario sería percibido por los trabajadores que no alcanzan el salario mínimo. Es una propuesta ya aplicada en otros países, como Inglaterra y Estados Unidos. Ciudadanos plantea un coste de alrededor de 7.000 millones de euros (el primer año 1.300 millones de euros y en los tres siguientes 2.100 millones). 5

Esta propuesta sobre un complemento salarial garantizado se complementa con otra para atender a la pobreza infantil, la contenida en el art. siguiente al anterior, el 43, que expresa: "Plan de choque contra la pobreza infantil. Dotaremos una ayuda a los hogares por hijo a

\footnotetext{
${ }^{4}$ https://www.ciudadanos-cs.org/programa-electoral

5 Este complemento salarial garantizado formó parte del Acuerdo convenido en febrero de 2016 entre el PP y Ciudadanos, aunque no prosperó en la legislatura. El Acuerdo fue un pacto de investidura, lo que supone que el PP puede quitarle importancia, pero también Ciudadanos puede exigirlo como condición del mantenimiento del Gobierno.
} 
cargo para combatir de forma eficaz la pobreza infantil. La prestación será mayor para las familias de menores ingresos, y se reduciría gradualmente según aumenten. La prestación será compatible con otro tipo de ayudas y rentas como el complemento salarial." Se deduce del artículo que son complementarios la ayuda en favor de la pobreza infantil y el complemento salarial garantizado.

La propuesta de Ciudadanos está contemplada para quienes tienen un trabajo precario; no para quienes carecen de trabajo. De mayor a menor protección social se sitúa en el tercer puesto de las propuestas de los partidos políticos. Primero: renta básica universal. Segundo: renta garantizada para quienes no tienen trabajo o éste es precario. Tercero: complemento salarial para los trabajadores con salarios precarios. El CSAG de Ciudadanos se presenta más alejado de una renta básica universal que las propuestas del Partido socialista y de Podemos, como veremos.

\subsection{Partido Socialista Obrero Español: ingreso mínimo vital.}

El PSOE propone un ingreso mínimo vital, una especie similar a las pensiones no contributivas dirigidas a las personas que carecen de ingresos o se encuentran en una situación vulnerable e indigente. Es la última prestación para quienes ya hayan agotado todas las prestaciones. Una especie de última cobertura de la indigencia. Por ello se activa cuando ya no hay posibilidad de subsidio de desempleo y deja de existir cuando el beneficiario pasa a situación de empleo. Las cuantías de ambos -subsidio de desempleo e ingreso mínimo vital- es la misma. Pero las cantidades varían en función del número de los hijos, que suponen un complemento económico por encima de la cifra del ingreso mínimo vital. Se ubica en la Seguridad Social, de la misma manera que las pensiones no contributivas. No necesita causas concretas, sino el hecho del desamparo en prestaciones.

Así expresa el PSOE su propuesta: "Es una renta básica que actúe como última red de protección social para atender a las personas que queden desamparadas. Consiste en la creación de una prestación nueva dirigida a los hogares sin ingresos y en situación de necesidad, sea cual sea la causa, como Prestación No Contributiva de la Seguridad Social, similar a las Pensiones No Contributivas. Articulado en coordinación con el Subsidio por Desempleo, con iguales cuantías, de forma que, una vez agotada la protección por desempleo, permita el paso entre ambos sistemas manteniendo siempre la cobertura de la prestación. Esta medida se diseña como la última red de protección, cuando persista la necesidad, una vez agotadas las medidas vinculadas al nuevo marco de convivencia, dirigidas a la inclusión económica, social y laboral y de mejora de la protección por 
desempleo (derechos, fiscalidad, educación, nuevo Estatuto de los trabajadores, SMI, etc. ). Dirigida a las 730.000 hogares sin ingresos". ${ }^{6}$

El programa electoral del PSOE explica su atención a este ingreso, porque han sido desatendidos los propósitos del Estado social y como consecuencia de ello se han originado diez importantes problemas, citando como número 3 la fractura del sistema de protección social, que ha conducido a la pobreza y exclusión social a un alto número de hogares. Así expresa este problema: "La ausencia de un mecanismo que garantice unos ingresos mínimos en caso de exclusión económica. Con ello, a falta de una malla de protección de última instancia, se ha condenado a cientos de miles de personas a situaciones de extrema vulnerabilidad, cuando no de exclusión permanente. Esa condena tiene un alto coste social. Trunca itinerarios vitales, dificulta la reintegración a una vida normalizada, restando oportunidades a estas personas para realizar aportaciones valiosas a la sociedad". " El programa señala diez propuestas para solucionar los problemas aducidos incluyendo como segunda propuesta: "Desarrollar un sistema público de garantía de ingresos mínimos vitales, que ofrezca recursos a las familias que estén en situación de especial vulnerabilidad y/o en riesgo de exclusión social".

A continuación el programa electoral dedica un apartado a la regulación del ingreso mínimo vital dentro del capítulo "Medida de choque contra la desigualdad: el Ingreso Mínimo Vital", cuyo contenido es el siguiente: "Establecer mediante una Ley un sistema de garantía de Ingreso Mínimo Vital de carácter no contributivo. Este sistema ofrecerá recursos mínimos a familias en situación de vulnerabilidad o en riesgo de exclusión social. El Sistema incluirá:

A. Crear una prestación nueva dirigida a los hogares sin ingresos o en situación de necesidad, sea cual sea la causa, como prestación no contributiva de la Seguridad Social. Para su reconocimiento, la Seguridad Social contará con la colaboración de los servicios sociales de las CCAA; mediante pacto con éstas, la gestión de esta prestación se coordinará con los Planes de Inclusión Social y de Atención Integral a la Familia.

B. Incrementar la cobertura de la prestación por hijo a cargo y aumento de la cuantía, de forma escalonada, en función de las rentas familiares. Solo estará vinculado a los ingresos del hogar independientemente de la situación laboral de los padres.

El campo de protección social que pretende abarcar el PSOE con sU propuesta es considerable: 730.000 familias y 1.847 .000 personas, aplicando la media de 2,53 personas por hogar, siguiendo la estadística del INE.

\footnotetext{
${ }^{6} \mathrm{http} / / /$ www.psoe.es/propuestas/politica-social/ingreso-minimo-vital/

7 Ésta y las siguientes citas son extraídas del programa electoral del PSOE. Elecciones generales 2016: PSOE-Programa-Electoral-2016.pdf
} 
Por lo tanto, el objetivo del ingreso mínimo vital es atender a las personas y familias que carecen de un subsidio de desempleo, porque o no tienen trabajo o lo han tenido, pero se les ha acabado los subsidios concatenados a la pérdida de empleo. Procura que todos los ciudadanos estén amparados por un ingreso. Supone un cambio a mejor de la situación actual de desamparo de muchas personas, pero no llega al arco de protección de la renta básica universal, que se concede por el Estado a todos por el mero hecho de ser ciudadano español, incondicionadamente, sin ningún tipo de contraprestación, posición, acción, etc. por parte del beneficiario. Tienen derecho a la renta básica universal del mismo modo que disfrutan de las libertades fundamentales.

\subsection{Podemos: renta complementaria garantizada}

Podemos sorprendió con una apuesta arriesgada en las elecciones europeas de 2014: la de un renta básica universal, es decir, una prestación económica que los españoles recibirían por el mero hecho de ser españoles, sin ningún otro tipo de condicionamiento, fijando la cantidad de la misma en al menos la cifra del umbral de la pobreza. En las elecciones de diciembre de 2015 abandonó esta propuesta y la sustituyó por la de una renta garantizada. Propuesta que mantuvo en la elecciones de junio de 2016, aunque bajando la cifra del coste. Los quince mil millones de euros de diciembre de 2015, beneficiándose 7,8 millones de personas, pasaron a diez mil millones de euros en junio de 2016, beneficiándose solamente 2,6 millones de personas. Se trata como la de Ciudadanos de una renta complementaria salarial para las personas que recibieran ingresos por debajo del umbral de la pobreza (o no recibieran nada)

J. L. Rey, tratadista de la renta básica, se queja de la retirada de la propuesta, por derivar hacia posiciones más conservadoras con la finalidad de allegar nuevos votos. ${ }^{8}$

Podemos se atrevió incluso a indicar cifras de la renta para las familias de un solo miembro, 600 euros, aumentando en función del número de miembros (35\% para el segundo miembro, y $20 \%$ para cada uno de los siguientes, hasta un máximo de 1.290 euros).

Los puntos del programa electoral de Podemos referidos a la renta garantizada son los puntos 78, 101 y 102. El punto 78 establece "la asignación de 15.000 millones de euros anuales para un Plan de Bienestar Social y Modernización Económica que incluirá una renta garantizada, la mejora salarial y la reversión de los recortes sufridos desde 2010". El punto 101 ya se refiere directamente a la renta

8 www.sinpermiso.info. 1 de noviembre de 2015. 
garantizada, que es la expresión que aparece en el enunciado, cuyo contenido transcribo en este texto y no en nota a pie de página por su importancia: "Crearemos un programa de renta diferencial (complementaria de los ingresos existentes) para todos los hogares con ingresos por debajo del umbral de pobreza monetaria, para lo que aumentaremos la cuantía de la prestación básica por persona integrada en la unidad de convivencia. La cuantía inicial se establecerá en 600 euros mensuales para las unidades de convivencia de un solo miembro, y aumentará progresivamente en función del número de miembros (35\% adicional de la renta garantizada para el segundo miembro, y $20 \%$ por cada uno de los siguientes) hasta un máximo de 1290 euros. Este plan integrará todas las prestaciones sociales que se encuentren por debajo de ese umbral." Este punto sobre la renta garantizada es complementado con el 102, cuyo fin es establecer "una retirada graduada de la renta garantizada" en la medida en que la situación de su beneficiario mejore. En este punto el enunciado es "renta complementaria", (que en los textos de Podemos se intercambia con la de "renta garantizada"), por lo que considero que quizás la mejor denominación sea la de "renta complementaria garantizada".9

La renta garantizada propuesta por Podemos es finalmente no una renta básica universal, a la que se tiene derecho por ser persona 0 nacional del Estado español (como se configuraba el su programa electoral en las elecciones europeas de mayo de 2014), sino una renta de determinadas personas en situación de pobreza y que la disfrutarán durante el tiempo que sufran esa situación precaria.

No obstante, Podemos es el partido que más se acerca a la renta básica universal, porque su arco protector de los sin trabajo o trabajos precarios es mayor que las propuestas de otros partidos. La proximidad a la renta básica universal se inserta en una propuesta de mayor calado: la asimilación de los derechos sociales a las libertades individuales, obteniendo éstos la misma cualificación jurídica de las libertades individuales, lo que entrañaría una reforma constitucional. 10

\footnotetext{
9 El contenido de este punto 102 es el siguiente: "Programa de Renta Complementaria. Estableceremos un complemento para trabajadores con baja remúneración para eliminar la discriminación que supone la utrampa de la pobreza», y para garantizar el acceso de estos trabajadores a niveles suficientes de bienestar. Para aquellos beneficiarios de la Renta Garantizada que trabajen o encuentren empleo, supondría, de hecho, una retirada graduada (y no súbita) de la prestación conforme vayan aumentando sus ingresos salariales. Lo anterior supondrá garantizar unos ingresos mínimos de 900 euros mensuales para estos trabajadores, que también se incrementarán con el número de miembros de la unidad de convivencia. Este complemento solo será efectivo a partir de unos ingresos reconocidos del trabajo por encima de 250 euros, para evitar posibles situaciones de fraude.

10 En nuestra Constitución los derechos sociales - a la salud, al trabajo, a la vivienda, etc. - carecen de la categoría jurídica de las libertades -los verdaderos y eficaces derechos- , las cuales son auténticos derechos subjetivos recurribles ante los tribunales, en tanto los derechos sociales no son derechos de las personas, sino normas orientativas y programáticas dirigidas a los poderes públicos para su promoción.
} 
En este sentido Podemos defiende la reforma del artículo 53 de la Constitución para equiparar los derechos económicos, sociales y culturales a los derechos civiles y políticos (contenido del punto $135 \mathrm{del}$ programa electoral). ¿¿Cómo conseguir la renta garantizada complementaria? Por una serie de medidas entre las que destacan la tasa "Tobin" para las transacciones financieras y el impuesto global sobre la riqueza, que forman parte del punto 135 citado titulado "Garantía constitucional de los derechos sociales". Las medidas expresadas en el art. 135 son: a) El estudio de la creación de un impuesto global sobre ta riqueza que grave gradualmente los grandes patrimonios como garantía de los derechos sociales, b) La adopción de un impuesto sobre las transacciones financieras y c) La fijación de una definición universal y normativa vinculante para los paraísos fiscales.

\section{Las vías y modalidades de reconocimiento jurídico de la renta básica universal. La posición de los programas electorales de los partidos políticos}

La posición de la doctrina no es ni unánime ni pacífica a la hora de plantear la fórmula de reconocimiento de la renta básica en el ordenamiento jurídico. Es lógico, pues se trata de un derecho naciente y en gestación. Podemos distinguir tres propuestas. a) como derecho social, b) como libertad y c) como garantía de un derecho.

1. La consideración de la renta básica como derecho social es la dominante. Bien entendido que se trata de un derecho ad futurum aún no reconocido en el ordenamiento jurídico de los Estados avanzados, salvo alguna excepción, como se ha indicado. El derecho a una renta básica universal sería el derecho de cierre de una trayectoria de los derechos sociales en un lento caminar desde el siglo XIX: derecho al trabajo, al salario, a las vacaciones, a la salud, a la educación, a la vivienda... y finalmente el derecho a una renta para subvenir a las necesidades básicas. El derecho que completa la lista de los derechos sociales. La inserción de la renta básica universal en esta lista de los derechos sociales presenta una evidente justificación, pues esta renta demanda una prestación del Estado y los derechos sociales en general comportan una prestación de los poderes públicos, obligados a prestar a las personas salud, educación, vivienda, etc.

Podemos asegurar que los filósofos del derecho y los constitucionalistas, cuando se refieren este derecho non nato, la renta básica universal, lo catalogan en términos de derecho social, de manera que, si alguna vez fuera incorporado al ordenamiento jurídico, lo seria mediante la estructura jurídica de un nuevo derecho social, completando la lista de

Podemos acudir a los tribunales exigiendo la reparación de un delito contra nuestras libertades, pero no el derecho a un trabajo o una vivienda. 
los actuales derechos sociales, y tendría la naturaleza jurídica de los derechos sociales y sus limitaciones siempre por debajo de las libertades individuales. Los filósofos del derecho y constitucionalistas suelen considerar a las libertades como derechos a la no interferencia del Estado abstencionista, mientras que los derechos sociales son derechos a una prestación dispensada por el Estado, como realmente es la pretensión de una renta básica universal. Formaría parte, por lo tanto, del número de los derechos humanos de segunda generación. Los tratadistas de la Constitución española colocan una línea de separación entre las libertades y los derechos sociales, las primeras auténticos derechos subjetivos, y por lo tanto susceptibles de recurso ante su vulneración, y los segundos normas dirigidas a los poderes públicos y no derechos subjetivos como las libertades, y como consecuencia no son susceptibles de recursos en los casos de vulneración. Por ello tiene una especial importancia que un derecho sea calificado jurídicamente como libertad o derecho social. La propia Constitución ya establece esta diferencia de tratamiento y consecuencias jurídicas al diseñar la sección $1^{a}$ del capítulo II para los "derechos fundamentales y las libertades públicas" (arts. 15 a 29) y el capítulo III para "los principios rectores de la política social y económica" (arts. 39-52), en el que se incluyen los derechos sociales. Finalmente los arts. 53 y 54 otorgan una protección especial a los primeros de la que carecen los segundos.

2. La concepción de la renta básica universal como libertad real ha tenido como punto de referencia a Phillipe van Parijs, filósofo belga, perteneciente al Colectivo Fourier ${ }^{11}$, que con su equipo de trabajo puso de actualidad la renta básica universal argumentando que su introducción en los países avanzados daría la vuelta a las teorías políticas, puesto que esta renta podría ser el instrumento de una vía capitalista hacia el socialismo. ${ }^{2}$ Esta aseveración -la relación de la renta básica y el capitalismo- provocó un aluvión de debates y monografías que tuvo la virtualidad de poner en candelero el tema de la renta básica universal.

Van Parijs piensa que la renta básica universal, a la que denomina ingreso básico, significa el derecho a la libertad real, ya que según él se es libre cuando se dispone de los medios para atender a las oportunidades. (Van Parijs, 2006: 53 ss.) Los derechos no valen si no vienen provistos de medios para alcanzar tos objetivos que brindan las oportunidades. La renta básica universal hace posible la libertad de

\footnotetext{
11 Charles Fourier, socialista utópico del siglo XIX, fue uno de los impulsores de la renta básica universal. Los promotores de la misma coordinados por Van Parijs en el último tercio del siglo XX se reunieron y la dieron a conocer a la opinión pública bajo el nombre del socialista francés.

12 El artículo "Una vía capitalista al comunismo", redactado por Van Parijs y Van der Beer, fue publicado en la revista Theory and Society (núm. 15, 1986), y puede ser consultado en la revista Zona Abierta, 1988, pp. 19-45.
} 
todos, que de otra manera sería atributo de los pocos que dispusieran de medios o recursos.

3. La renta básica universal no es propiamente un derecho, sino la garantía de un derecho. Es la opinión de J. L. Rey que la considera como una garantía del derecho del trabajo concebido como derecho a la inserción en la sociedad. ${ }^{13}$

¿Cuál es la posición de los partidos políticos en su programas electorales de 2016 respecto a la cualificación jurídica de la renta básica universal? Muy lejos de definirla como un derecho y menos aun como un derecho de carácter permanente. No es una modalidad de libertad real, tampoco es un derecho social; más bien una garantía que se actualiza cuando no hay trabajo y la persona no puede percibir un salario o éste salario está por debajo del umbral de la pobreza. Lo que explica que se incluya en los programas de los partidos políticos bajo los rótulos de "Combatir la exclusión social", "Medida de choque contra la desigualdad", "Estado del bienestar", etc. Diríamos que la posición de los programas de los partidos políticos se acercan a la consideración del punto tercero del epígrafe anterior: la concepción de la renta básica (no universal) como garantía de un derecho, del que tampoco se predica su carácter de derecho subjetivo permanente y susceptible de recursos si es objeto de vulneración.

Tiene sentido esta cautela en la cualificación de una renta básica y no universal, porque los partidos son conscientes de que están proponiendo una medida social atrevida, que puede dar al traste o dañar sensiblemente las arcas del Estado, y que puede encontrar la oposición de amplias mayorías sociales, las cuales se tentarán sus propios bolsillos antes de pronunciarse. Estas circunstancias probablemente justifiquen la resistencia de los partidos políticos a emplear el término "derecho" y prefieran hablar de "medida social" (PP), "complemento salarial anual garantizado" (Ciudadanos), "ingreso mínimo vital" (PSOE) y "renta garantizada complementaria" (Podemos).

\section{Los fundamentos de la renta básica universal. La posición de los programas electorales de los partidos políticos}

R. Soriano (2012: 37-54) en su libro "Por una renta básica universal. Un mínimo para todos" enumera y explica los argumentos a favor y en contra del establecimiento de una renta básica universal. Dejamos a un lado los argumentos contrarios, porque no atañen a la finalidad de este trabajo. Entre los argumentos favorables cita los siguientes:

13 J. L. Rey Pérez refleja esta opinión en un extenso volumen dedicado a la inserción social y el derecho del trabajo, El derecho al trabajo y el ingreso básico ¿̇Cómo garantizar el derecho al trabajo? (2010). Una síntesis en Revista Internacional de Pensamiento Político, 5, 2010, p. 205. 
El principio de igualdad de oportunidades

La renta básica universal como derecho presupuesto de otros derechos

La erradicación definitiva de la pobreza

La dignidad de la persona frente al estigma social

La supresión de la ficción del desempleado

La supresión del carácter político de los subsidios: instrumentos de estabilidad social

La consecución de la libertad real de las personas como derivado de su independencia material

La materialización y culminación de las aspiraciones del Estado social

Enunciados los argumentos, ¿cuál es la posición de los programas electorales de los partidos políticos? ¿Hay en ellos alusiones a alguno o algunos de los fundamentos indicados? En principio parece que el tema merece un desarrollo en el texto de los programas de los partidos políticos, pues se refiere a una cuestión caliente y controvertida, en la que además hay evidentes diferencias entre los partidos. Una renta básica universal o figuras afines sorprenden a la mayoría social y a muchos que verán dos problemas para su implantación: que no se corresponde con el trabajo de los beneficiarios y que puede "comerse" desmesuradamente los ingresos del Estado. Pero no encontramos en los programas electorales una amplia explicación justificatoria por parte de quienes plantean una figura próxima a la renta básica universal. Hay una amplia enumeración de razones que justifican las medidas sociales a tomar: "la exclusión social", "las personas vulnerables", "el bienestar social", "la erradicación de la pobreza", "los fines del Estado social", "la igualdad de oportunidades", etc., pero no van acompañadas de párrafos explicativos o éstos son escasos. Lo cual no tiene mucha razón de ser, porque los programas no se presentan como textos articulados, sino enunciativos, donde tendría sentido una explicación, si bien somera, de medidas tan nuevas y de carácter social.

El PP alude como argumentos la erradicación de la pobreza y la exclusión; cita estas dos palabras como fines de sus nuevas leyes y las coloca en los enunciados de las mismas: "El PP se compromete asegura el programa- a seguir luchando contra la pobreza y la exclusión promoviendo una ley básica de Servicios Sociales de ámbito nacional, una Estrategia Nacional de Lucha contra la Pobreza, con especial atención a los jóvenes y a los casos crónicos; un nuevo Plan de Inclusión Social 2016-2020, y la coordinación de un mapa común de Rentas Mínimas de Inserción de las distintas Comunidades Autónomas para favorecer la igualdad de oportunidades." A destacar como fundamento -que no está en los programas de los otros partidos- la igualdad de oportunidades de las personas mediante la coordinación 
de los programas de rentas mínimas de inserción de la totalidad de las Comunidades autónomas.

Bajo el título "Combatir la exclusión social" de su programa electoral el PP propone una serie de medidas ya indicadas en el epígrafe 2 bajo el siguiente enunciado general: "La superación de la pobreza y la exclusión social constituye uno de los grandes retos de nuestro tiempo. El Partido Popular asume el compromiso firme de combatirlas y de dar prioridad a todas las medidas que favorezcan la inclusión social, laboral y educativa, y que permitan una nueva oportunidad para todo el que la necesite."

Ciudadanos propone el complemento salarial anual garantizado motivado por dos luchas: la lucha contra la pobreza laboral y la lucha contra la economía sumergida. "Será una devolución de Hacienda afirma el programa- para luchar contra la pobreza laboral... Es prioritario reconstruir la clase media trabajadora y luchar contra la economía sumergida."

Es curiosa la referencia a la pobreza laboral, porque se concentra en un tipo de pobreza, la que es motivada por falta de empleo, como si no tuvieran que ser atendidas otras clases de pobrezas, las originadas por otras causas que no sea la falta de trabajo. Y también llama la atención la referencia a la economía sumergida como razón y fin al mismo tiempo del complemento salarial, que no está presente en el apartado de renta básica de los programas de los otros partidos. También sorprende que la existencia de este complemento salarial ayude a "reconstruir la clase media trabajadora", porque evidentemente su beneficio únicamente ayudará a quienes ocupan los últimos peldaños en la escala social y no a las clases medias.

El Partido Socialista plantea el ingreso mínimo vital dentro del capítulo "Medida de choque contra la desigualdad: el Ingreso Mínimo Vital", cuyo contenido es el siguiente: "Establecer mediante una Ley un sistema de garantía de Ingreso Mínimo Vital de carácter no contributivo. Este sistema ofrecerá recursos mínimos a familias en situación de vulnerabilidad o en riesgo de exclusión social." Por lo tanto ahí están los tres motivos de este tipo de ingreso para los socialistas: la vulnerabilidad de las personas y el riesgo de exclusión social dentro de la lucha contra la desigualdad. El programa también alude a "la fractura del sistema de protección social", que es la causa general del desamparo de miles de hogares familiares.

Podemos asocia la renta básica a su concepción del Estado como Estado social o Estado del bienestar y la defensa de los derechos sociales al mismo nivel que las libertades individuales Por eso al enfrentarse al tema de la renta garantizada complementaria la enmarcan en el contexto de "las políticas sociales que refuercen el Estado de bienestar y los servicios públicos relacionados con la atención a las personas" (punto 78 de su programa electoral). Para este partido 
esta renta es necesaria en la medida en que está por construir un Estado verdaderamente social y unos derechos sociales efectivos. Por lo demás la erradicación de la pobreza sobrevuela los textos amplios del programa dedicados a la configuración de la renta garantizada complementaria, que se recibe cuando las personas están por debajo del umbral de la pobreza y se abandona en la medida que éstas alcanzan un estatus por encima de ese umbral. Por eso el art. 101 del programa electoral se abre así: "Crearemos un programa de renta diferencial (complementaria de los ingresos existentes) para todos los hogares con ingresos por debajo del umbral de pobreza monetaria." Los fundamentos, pues, de esta renta son la erradicación de la pobreza y la necesidad de avanzar en la conquista de los derechos sociales.

En resumen, del conjunto de fundamentos consignados en el inicio de este epígrafe los partidos políticos seleccionan como justificación de la renta básica o figuras afines presentadas en sus programas electorales los siguientes: "el principio de igualdad de oportunidades", "la erradicación de la pobreza", "la materialización y culminación de las aspiraciones del Estado social" y "la supresión de la ficción del desempleado" (traducida en los programas de los partidos como lucha contra la economía sumergida).

\section{Conclusiones}

Ninguno de los programas electorales, con los que los partidos políticos concurrieron a las elecciones generales de 2016, ha incorporado la renta básica universal. El Partido Popular se ha limitado a una mejor regulación de los subsidios existentes de protección social, añadiendo la promoción de la igualdad en las prestaciones recibidas con independencia de la Comunidad Autónoma donde se resida.

Ciudadanos se ha preocupado por los salarios y trabajadores precarios planteando un complemento salarial anual garantizado para los trabajadores cuyos ingresos estén por debajo del salario mínimo. No prevé protección para quienes no tienen trabajo, con lo que un importante contingente de personas se queda sin la protección social garantizada. La cuantía del complemento salarial depende del nivel de ingresos y los componentes del hogar familiar.

El Partido Socialista defiende un ingreso mínimo vital, tanto para quienes tienen trabajo como para los que carecen de él y han agotado todas las prestaciones de desempleo, siempre que se encuentren en una situación de desamparo. Una vez que los desamparados vuelven al empleo dejan de percibir el mínimo vital garantizado. La cuantía de este ingreso aumenta con el número de personas que constituyen el hogar familiar. Supone la protección de un mayor número de 
desprotegidos que los derivados del complemento salarial garantizado de Ciudadanos.

Podemos ha incorporado a su programa electoral una renta complementaria garantizada para todas las personas que se encuentren por debajo del umbral de la pobreza, tengan o no trabajo. Cada persona en situación de pobreza recibirá 600 euros mensuales, cantidad que aumentará dependiendo del número de componentes del hogar familiar. La renta desaparece cuando se alcanza un trabajo por encima del umbral de la pobreza. Comporta la protección de un mayor número de personas que las protegidas por el ingreso mínimo vital del Partido Socialista.

La renta básica universal hizo acto de presencia por una y definitiva vez en el programa electoral, con el que Podemos hizo su debut en las elecciones europeas de 2014; era una renta para todas las personas por el mero hecho de ser persona. Posteriormente Podemos retiró la renta básica universal de sus futuros programas electorales, no obstante plantear en su lugar un tipo de renta más cercana a la renta básica universal que la ofrecida por el resto de los partidos políticos.

Los partidos políticos no se atreven a llamar derecho a sus propuestas de renta básica (o figuras afines), probablemente debido a la dificultad de aceptación de esta medida por las mayorías sociales. Menos aun denominarlas como un derecho permanente o recurrible, como un verdadero derecho subjetivo.

Tampoco explican con detalles los fundamentos de la renta básica (o figuras afines) que proponen; meramente los enuncia destacando: la igualdad de los españoles de las distintas Comunidades Autónomas, la erradicación de la pobreza, la ayuda a las personas vulnerables, la lucha por el Estado social y los derechos sociales y la supresión de la economía sumergida.

\section{Bibliografía}

Ackerman, B., Alstott, A. (1999), The Stakenholder Society, New Haven: Yale University Press.

Arcarons, J, Boso, A., Noguera, J.A., Raventós, D. (2005), Viabilitat i impacte d'una Renda Bàsica de Ciutadania per a Catalunya, Barcelona: Mediterrània-Fundació Jaume Bofill.

Atkinson, A.B. (1996) The case for a participation income, The Political Quaterly, 67-70. 
Colectivo Charles Fourier (1991), Una vía capitalista al comunismo. El salario social garantizado, Madrid: Fundación de Investigaciones marxistas.

Dahrendorf, R. (2005), En busca de un orden nuevo. Una política de la libertad para el siglo XXI, Barcelona: Paidós.

Debate de RIPP (2010), La Renta Básica, Revista Internacional de Pensamiento Políitico, 5, 2010, 199-208.

Ferrajoli, L. (1996), El Estado constitucional de Derecho hoy: el modelo y su divergencia de la realidad". En P. Andrés Ibáñez (ed.) Corrupción y Estado de Derecho. El papel de la jurisdicción (pp. 15-30), Madrid : Trotta.

Ferrajoli, L. (2001), Derechos y Garantías. La ley del más débil, Madrid: Trotta,

Fourier, Ch. (1973), La armonía pasional del nuevo mundo, Madrid: Taurus.

Fromm, E. (1956), Psicoanálisis de la sociedad contemporánea, México: FCE.

Gorz, A. (1998), Miserias del presente, riquezas del futuro, Buenos Aires: Paidós.

Hayek, F.A. (1988), Derecho, legislación y libertad, II: El espejismo de la justicia social, Madrid: Unión Editorial.

Iglesias, J. (2004), Las culturas de las rentas básicas. Historia de un concepto, Barcelona: Virus Editorial.

Lo Vuolo, R. (com.) (1995), Contra la exclusión (La propuesta del ingreso ciudadano), Buenos Aires: Ciepp/ Miño y Dávila.

Marx, K. (1982) Escritos de juventud, México: FCE.

Negri, T. (1998), El exilio, Barcelona: El Viejo Topo.

Offe, C. (1995), Un diseño no productivista para las políticas sociales. En Rubén lo

Vuolo (com.), Contra la exclusión. La propuesta del ingreso ciudadano, Buenos Aires: Ciepp/Miño y Ávila Editores.

Paine, Th. (1990), El sentido común y otros escritos, Madrid: Tecnos (trad. de R. Soriano y E. Bocardo)

Pinilla, R. (2006), Más allá del bienestar. La renta básica de ciudadanía como innovación social basada en la evidencia, Barcelona: Icaria.

Pisarello, G. y Del Cabo, A. (eds.) (2006), La renta básica como nuevo derecho ciudadano, Madrid: Trotta.

Raventós, D. (1999), El derecho a la existencia, Barcelona: Ariel. 
Raventós, D. y Soriano, R. (2010), La Renta Básica ¿ Una propuesta justa, razonable y posible?, Revista Internacional de Pensamiento Político, 5, 189-198.

Rawls, J. (1996), El Liberalismo Político, Barcelona: Crítica.

Real Academia Española (1997), Diccionario de la Lengua Española. Voz "Subsistencia", Madrid: Espasa Calpe, tomo II, p. 1912.

Rey, J.L. (2007), El derecho al trabajo y el ingreso básico ¿Cómo garantizar el derecho al trabajo?, Madrid: Dykinson.

Robespierre, M. (1992), La Revolución jacobina, Barcelona: Edicions 62.

Sandel, M. (2000), El liberalismo y los límites de la justicia, Barcelona: Gedisa.

Soriano, R. (2011), Teorías políticas clásicas y renta básica universal, Sistema, 222, 95-210.

Soriano, R. (2012), Por una renta básica universal. Un mínimo para todos, Córdoba: Almuzara.

Soriano González, M.L. (2012), La renta básica y el derecho de subsistencia en Luigi Ferrajoli, Cuadernos Electrónicos de Filosofía del Derecho, 26, 232-249.

Susín, R. (2000), La regulación de la pobreza. El tratamiento jurídicopolítico de la pobreza: Los ingresos mínimos de inserción, Logroño: Servicio de Publicaciones de la Universidad de la Rioja.

Van Parijs, Ph. (1988), Una vía capitalista al comunismo, Zona Abierta, 1988, 19-45.

Van Parijs, Ph. (1996), Libertad real para todos. ¿Qué puede justificar al capitalismo (si hay algo que puede hacerlo)? Barcelona: Paidós.

Van Parijs, Ph. y Venderborght, Y. (2006), La Renta Básica. Una medida eficaz para luchar contra la pobreza, Barcelona: Paidós.

White, S. (2003), The Civic Minimum. On the rights and obligations of economic citizenship, Oxford, Oxford University Press.

VV.AA. (2015), Empleo precario y protección social, Madrid: Fundación Foessa-Cáritas Española.

\section{PROGRAMAS ELECTORALES 2016 DE LOS PARTIDOS POLÍTICOS}

CIUDADANOS: https://www.ciudadanos-cs.org/programa-electoral

PARTIDO POPULAR: programa_electoral_pp_2016.pdf

PARTIDO SOCIALISTA: psoe-programa-electoral-2016.pdf

PODEMOS: https://lasonrisadeunpais.es/programa/ 